\title{
Photocatalytic Template Removal by Non-Ozone-Generating UV Irradiation for the Fabrication of Well-Defined Mesoporous Inorganic Coatings
}

\author{
Barry Reid, ${ }^{\dagger}$ Alaric Taylor, ${ }^{\dagger}$ Al Alberto Alvarez-Fernandez, ${ }^{\dagger}$ Muhamad Hafiz Ismael, ${ }^{\dagger}$ Shatakshi Sharma, ${ }^{\dagger}$ \\ Benjamin Schmidt-Hansberg, ${ }^{*}$ and Stefan Guldin*,† \\ ${ }^{\dagger}$ Department of Chemical Engineering, University College London, Torrington Place, London WC1E 7JE, U.K. \\ ${ }^{*}$ BASF SE, Process Research \& Chemical Engineering, Coating \& Film Processing, Carl-Bosch-Strasse 38, Ludwigshafen am Rhein \\ 67056, Germany
}

\section{Supporting Information}

ABSTRACT: The processing of mesoporous inorganic coatings typically requires a high-temperature calcination step to remove organic precursors that are essential during the material assembly. Lowering the fabrication energy costs and cutting back on the necessary resources would provide a greater scope for the deployment in applications such as architectural glass, optical components, photovoltaic cells, and energy storage, as well as further compatibilize substrates with low temperature stability. Organic removal methods based on UV-ozone treatment are increasing in popularity, but concerns remain regarding large-scale ozone generation and usage of mercury-containing UV lamps. To this end, we present a method that relies on non-ozone-generating UV radiation at $254 \mathrm{~nm}\left(\mathrm{UV}_{254}\right)$ and incorporation of small amounts of photocatalytic material in the formulation, here demonstrated with $\mathrm{TiO}_{2}$ nanocrystals. At concentrations as low as $5 \mathrm{wt} \%$ relative to the main inorganic aluminosilicate material, the $\mathrm{TiO}_{2}$ nanocrystals catalyze a "cold combustion" of the organic components under $\mathrm{UV}_{254}$ irradiation to reveal a porous inorganic network. Using block copolymer-based coassembly in conjunction with photocatalytic template removal, we produce well-defined mesoporous inorganic thin films with controlled porosity and refractive index values, where the required processing time is governed by the amount of $\mathrm{TiO}_{2}$ loading. This approach provides an inexpensive, flexible, and environmentally friendly alternative to traditional organic removal techniques, such as UV-ozone degradation and thermal calcination.

KEYWORDS: block copolymer, mesoporous thin films, low-temperature processing, photocatalysis, cold combustion, ellipsometric porosimetry

\section{INTRODUCTION}

Mesoporous inorganic thin-film architectures have demonstrated importance in a range of applications including optical coatings, ${ }^{1}$ photovoltaic cells, ${ }^{2}$ energy storage, ${ }^{3}$ photocatalysis, ${ }^{4}$ sensing, ${ }^{5}$ and protective barriers. ${ }^{6}$ Methods for the generation of such coatings are multifold and typically involve the use of organic compounds as surfactants, porogens, or structuredirecting agents. Examples include the porogen-mediated packing of nanoparticles ${ }^{7,8}$ and the two-dimensional (2D) assembly of hollow or mesoporous spheres. ${ }^{9,10}$ Evaporationinduced self-assembly combines inorganic precursors with organic structure-directing agents such as small molecule surfactants, block copolymers (BCPs), or colloids. ${ }^{11-13}$ The use of BCPs in particular offers the ability to closely control the porosity and pore size of the final inorganic network. ${ }^{14-16}$ Following substrate coating and film annealing, the final processing step for all of the above fabrication routes involves the removal of the organic components to reveal a porous inorganic network. Typically, high-temperature calcination is used. However, this method is incompatible with temperaturesensitive substrates, such as plastics or films composed of thin metallic materials, and further incurs a high energy cost. Consequently, viable alternatives have been researched in recent years. Oxygen plasma-etching techniques apply ionized gas molecules at low pressures to react with and decompose the organic material. ${ }^{15,17}$ While this method is popular in laboratory environments, the requirement of expensive specialized equipment and operation at low pressure provides challenges to process scaling. Acid etching ${ }^{18}$ and solvent extraction $^{19,20}$ methods have proven somewhat successful in removing the organic template, but environmental concerns remain regarding large-scale solvent usage and disposal.

An alternative to the above involves the use of high-energy vacuum ultraviolet $(<200 \mathrm{~nm})$ radiation to degrade the organic

Received: January 19, 2019

Accepted: April 19, 2019

Published: April 19, 2019 
template. At wavelengths below $185 \mathrm{~nm}$, photons generate ozone radicals from atmospheric oxygen, which can then attack and remove the organic template. ${ }^{21} \mathrm{UV}$ light at $172 \mathrm{~nm}$ removed surfactant templates within a matter of hours to expose mesoporous silica thin films, ${ }^{22,23}$ and variation of pressure was found to control the time taken for the total template removal. ${ }^{23}$ While UV-ozone methods have proven capable of removing polymer and surfactant templates, health and safety concerns remain regarding the generation of ozone radicals in workplace environments, especially when increasing production up to industrial scales. Exposure to ozone, even at levels lower than stated by regulations, has the potential to cause long-term harm and should be avoided. ${ }^{24}$ Furthermore, vacuum ultraviolet light is generated by gas-discharge lamps, which require mercury for their operation. In contrast, $\mathrm{UV}_{254}$ radiation does not generate ozone radicals and is compatible with light-emitting diode (LED) technology. ${ }^{25}$ This means that $\mathrm{UV}_{254}$ radiation can be generated at low cost and in an environmentally friendly manner. $\mathrm{UV}_{254}$ is also widely used in water-treatment plants and is thus already well established in larger-scale applications. Previous attempts to compatibilize organic template removal with UV wavelengths longer than $200 \mathrm{~nm}$, included photoacid generator precursors ${ }^{26}$ and dilute hydrogen peroxide. ${ }^{27}$

Here, we present a photocatalytic method for the fabrication of well-defined mesoporous inorganic coatings derived from a poly(isobutylene)-block-poly(ethylene oxide) (PIB- $b$-PEO) amphiphilic BCP structure-directing agent. We incorporate small amounts of prefabricated $\mathrm{TiO}_{2}$ nanocrystals (NCs) ${ }^{28}$ into the hybrid thin films and study the efficiency of "cold combustion" of the organic material under $\mathrm{UV}_{254}$ light exposure. ${ }^{29}$ Prefabricated $\mathrm{TiO}_{2} \mathrm{NCs}$ were previously incorporated into mesoporous thin-film coatings for low temperature crystallization, ${ }^{30}$ capacitive charge storage, ${ }^{31}$ photocatalysis, ${ }^{32,33}$ self-cleaning, and antireflective applications. ${ }^{15}$ Herein, we evaluate their use for low-temperature, energy-efficient, and environmentally friendly mesoporous inorganic film processing.

\section{EXPERIMENTAL SECTION}

Preparation of Mesoporous Aluminosilicate Thin Films. $\mathrm{PIB}_{39}-b-\mathrm{PEO}_{36}$ was synthesized by BASF as reported previously $\left(M_{\mathrm{n}}\right.$ $4.85 \mathrm{~kg} / \mathrm{mol}$; polydispersity index 1.26). ${ }^{34}$ The aluminosilicate sol was prepared as previously described. ${ }^{1,15}$ Following complete hydrolysis of the aluminosilicate sol, it was diluted in the toluene/1-butanol azeotrope solvent mixture at $1000 \mathrm{mg} / \mathrm{mL}$ and mixed with the other materials as required. $\mathrm{TiO}_{2} \mathrm{NCs}$ were prepared via a nonhydrolytic sol-gel route as described in detail elsewhere. ${ }^{15,28,33}$ The glassware was cleaned, dried under vacuum, and flushed several times with argon for an inert, dry atmosphere. Then, chemicals were added in the following sequence: $5.75 \mathrm{~mL}$ of ethanol ( $>99.8 \%$ Analar); $1 \mathrm{~mL}$ of $\mathrm{TiCl}_{4}$ (99.9\%, Acros Organics); $19.2 \mathrm{~mL}$ of benzyl alcohol (99.8\% anhydrous, Sigma-Aldrich); and $0.23 \mathrm{~mL}$ of 1,3-propanediol (Merck). The solution was heated to $80{ }^{\circ} \mathrm{C}$ and stirred for $12 \mathrm{~h}$ under an inert atmosphere. The resultant mixture was washed with diethyl ether and centrifuged $(3500 \mathrm{rpm} ; 10 \mathrm{~min})$. The process was repeated three times, and the resulting precipitate was allowed to air-dry for $30 \mathrm{~min}$ before resuspending in the toluene/1-butanol azeotrope mixture at a concentration of $19.2 \mathrm{mg} / \mathrm{mL}$. To confirm the $\mathrm{TiO}_{2}$ content in the solution, an aliquot of the solution was dried and calcined in a furnace at $450{ }^{\circ} \mathrm{C}$. All hybrid solutions were prepared with a polymer-toaluminosilicate ratio of 1:3 to maintain similar porosity values for all samples. Each sample contained $5 \mathrm{mg}$ of polymer and $15 \mathrm{mg}$ of aluminosilicate material. Samples were then prepared with increasing amounts of $\mathrm{TiO}_{2}$ relative to the aluminosilicate content as outlined in
Table 1. Note the nomenclature "NC" with a percentage value to indicate the weight percentage of $\mathrm{TiO}_{2}$ nanocrystals present in the sample.

\section{Table 1. List of Samples Prepared During This Work}

\begin{tabular}{cccc} 
sample name & $\% \mathrm{TiO}_{2}$ loading & $\begin{array}{c}\text { mass of } \mathrm{TiO}_{2} \\
(\mathrm{mg})\end{array}$ & $\begin{array}{c}\text { volume of azeotrope } \\
(\mathrm{mL})\end{array}$ \\
$\mathrm{NC}_{0 \%}$ & 0 & 0 & 0.182 \\
$\mathrm{NC}_{5 \%}$ & 5 & 0.75 & 0.158 \\
$\mathrm{NC}_{10 \%}$ & 10 & 1.5 & 0.202 \\
$\mathrm{NC}_{25 \%}$ & 25 & 3.75 & 0.242 \\
\hline
\end{tabular}

Hybrid solutions were spin-coated on silicon wafers at $2000 \mathrm{rpm}$ for $20 \mathrm{~s}$ to produce thin films. Oxygen plasma (Diener Electronic Pico, $0.4 \mathrm{mbar}, 5 \mathrm{~min}$ ) was initially used to treat the silicon surface followed by cleaning with a high-pressure liquid-withdrawal $\mathrm{CO}_{2}$ cleaning apparatus (Megatech Ltd.) prior to deposition. All hybrid films were thermally annealed $\left(130^{\circ} \mathrm{C}\right.$ target temperature, $1{ }^{\circ} \mathrm{C} / \mathrm{min}$ ramp, 30 min dwell time). ${ }^{1}$ Annealed samples were then exposed to UV radiation (Vilber VL-325.G lamp, $254 \mathrm{~nm}, 3 \times 15 \mathrm{~W}$ ) at a distance of $10 \mathrm{~mm}$ in an enclosed chamber for specified periods of time. Selected reference samples were calcined in a furnace at $450{ }^{\circ} \mathrm{C}$ $\left(10^{\circ} \mathrm{C} / \mathrm{min} \mathrm{ramp}, 30 \mathrm{~min}\right.$ dwell time $)$.

Material Characterization. A spectroscopic ellipsometer (SE2000, Semilab) with a built-in ellipsometric porosimetry (EP) module was used to determine film thickness, refractive index (RI), porosity, and pore size distribution. All measurements were taken at an incident angle of $73^{\circ}$. The analysis was performed with the manufacturer software (Spectroscopic Ellipsometry Analyzer) using a Cauchy dispersion law. Before EP characterization, samples were placed on a hotplate at $120{ }^{\circ} \mathrm{C}$ for several minutes to ensure that the pores were emptied of any adsorbed water molecules from the atmosphere. The sample porosity was determined with a LorentzLorenz effective medium approximation model based on the volume fraction of liquid water adsorbed within the pores. ${ }^{35}$ The pore size distribution was calculated with a modified Kelvin equation. ${ }^{36}$ Atomic force microscopy (AFM) was carried out on a Bruker Dimension Icon in ScanAsyst mode with a Bruker SAA-HPI-SS probe (nominal tip radius $1 \mathrm{~nm}$ ). Characterization by grazing incidence small-angle $\mathrm{X}$-ray scattering (GISAXS) was done on a SAXSLab Ganesha at an incidence angle of $0.2^{\circ}$. The structural fitting of the GISAXS data was completed using FitGISAXS software. ${ }^{37}$ The simulated GISAXS pattern was obtained with the same software based on a model of spherical objects arranged in a $2 \mathrm{D}$ hexagonal paracrystalline array. Raman spectroscopy measurements were obtained on a Thermo Scientific DXR Raman microscope with DXR $532 \mathrm{~nm}$ filter at an excitation wavelength of $532 \mathrm{~nm}$ ( $6 \mathrm{~mW}$ power) using an MPlan 50X objective. Powder X-ray diffraction (XRD) was performed on a Rigaku Smartlab X-ray diffractometer. Transmission electron micrographs were acquired on a $100 \mathrm{kV}$ JEOL CX 100 transmission electron microscope (TEM). X-ray photoelectron spectroscopy (XPS) was carried out on a Thermo Scientific K-Alpha photoelectron spectrometer. Samples were subjected to ion beam surface etching prior to acquisition of XPS spectra.

\section{RESULTS AND DISCUSSION}

Refractive index (RI) and porosity values were monitored using spectroscopic ellipsometry and environmental ellipsometric porosimetry (EP) techniques. RI values served as a first estimate to evaluate the effect of $\mathrm{UV}_{254}$ exposure on the initial hybrid films. Figure 1a shows the evolution of the RI of the coatings as a function of $\mathrm{UV}_{254}$ exposure time for two sets of samples, with no $\mathrm{TiO}_{2}$ nanocrystals incorporated $\left(\mathrm{NC}_{0 \%}\right)$ and with 5 wt $\% \mathrm{TiO}_{2}$ nanocrystals $\left(\mathrm{NC}_{5 \%}\right)$. X-ray diffraction (XRD) analysis (Figure S1, Supporting Information) of the dried $\mathrm{TiO}_{2}$ nanocrystals confirmed the presence of $\approx 3 \mathrm{~nm}$ $\mathrm{TiO}_{2}$ nanocrystals in the anatase phase as reported else- 

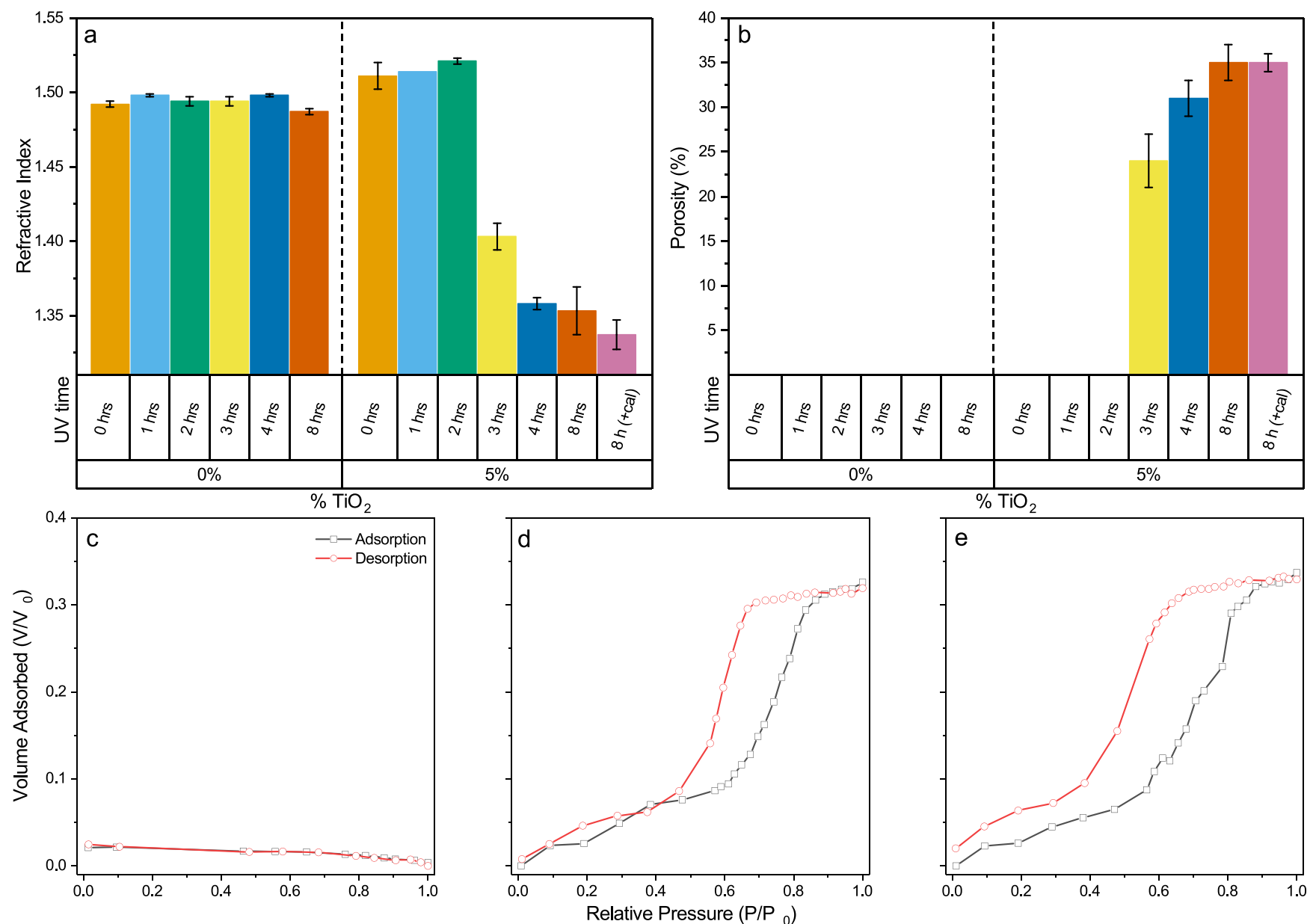

Figure 1. (a) Refractive index and (b) porosity change in $\mathrm{NC}_{0 \%}$ and $\mathrm{NC}_{5 \%}$ samples as a function of $\mathrm{TiO}_{2}$ content and UV exposure time. (c-e) Ellipsometric porosimetry adsorption/desorption isotherms of $\mathrm{NC}_{5 \%}$ (c) before $\mathrm{UV}_{254}$ exposure, (d) after $8 \mathrm{~h}$ of $\mathrm{UV}_{254}$ exposure, and (e) after $8 \mathrm{~h}$ of $\mathrm{UV}_{254}$ exposure with additional calcination at $450{ }^{\circ} \mathrm{C}$.

where. ${ }^{15,28,33}$ Transmission electron micrographs (Figure S2, Supporting Information) of $\mathrm{NC}_{5 \%}$ films demonstrate that the $\mathrm{TiO}_{2}$ nanocrystals are distributed throughout the aluminosilicate network. Similar results were observed in closely related studies employing block copolymer co-assembly of photocatalytic $\mathrm{TiO}_{2}$ nanocrystals and aluminosilicates. ${ }^{15}$ Note that both sets of coatings were subject to thermal annealing at 130 ${ }^{\circ} \mathrm{C}$ to remove volatile components from the film and promote the condensation of the inorganic network toward completion. $^{38}$ An observed decrease in RI at each subsequent processing step therefore served as an indicator for the degradation of material in the film. In this instance, the RI decrease corresponded to the removal of polymer material with a measured RI value of $\approx 1.5$ with air $(\mathrm{RI}=1)$.

$\mathrm{NC}_{0 \%}$ samples exhibited no RI change even when exposed to UV radiation for $8 \mathrm{~h}$. This conforms to expectations that wavelengths shorter than $185 \mathrm{~nm}$ are required to degrade organic material via the generation of ozone radicals from air, which, in turn, break the covalent bonds present in the organic material. ${ }^{21} \mathrm{NC}_{5 \%}$ exhibited no change in refractive index after 2 $h$ of UV exposure. After $3 \mathrm{~h}$, the RI value decreased significantly and reached a plateau with a little further reduction between 4 and $8 \mathrm{~h}$. Further calcination treatment at $450{ }^{\circ} \mathrm{C}$ [Figure $1(8 \mathrm{~h}+\mathrm{cal})$ ] elicited minimal RI change.

While the optical constants of the film are an effective route to observe changes in the film composition, they do not provide a comprehensive characterization of the porous network and pore accessibility in particular. Therefore, EP measurements were performed to probe the relative volume of the film available for capillary condensation of ambient water molecules at different stages of processing. Changes in the optical properties as a function of relative humidity can then be related to the accessible pore volume via an effective medium approximation (here, Lorentz-Lorenz), where the measured RI change of the coating as a whole is related to its constituent components. $^{15,39}$ In Figure $1 \mathrm{c}-\mathrm{e}$, we compare the EP adsorption/desorption isotherms for $\mathrm{NC}_{5 \%}$ samples before UV exposure, after exposure to UV for $8 \mathrm{~h}$, and after additional high-temperature calcination. In Figure 1c, little change was observed regardless of humidity, indicating that there were no accessible pores present in the initial hybrid material. For the 8 h sample (Figure 1d), the EP isotherm exhibited characteristics associated with type IV IUPAC isotherm designation. ${ }^{40}$ The isotherm classification, coupled with an $\mathrm{H} 2$ hysteresis loop, provides confirmation of a mesoporous material with "ink bottle" connections between the pores. The hysteresis observed in the desorption isotherm relates to the emptying of pores within the material, which is slowed by the narrow pore necks. $^{41,42}$ No further changes were observed in the isotherm characteristics when the $8 \mathrm{~h}$ sample was subsequently processed via thermal calcination, confirming that all of the template was removed via photocatalytic degradation (Figure 

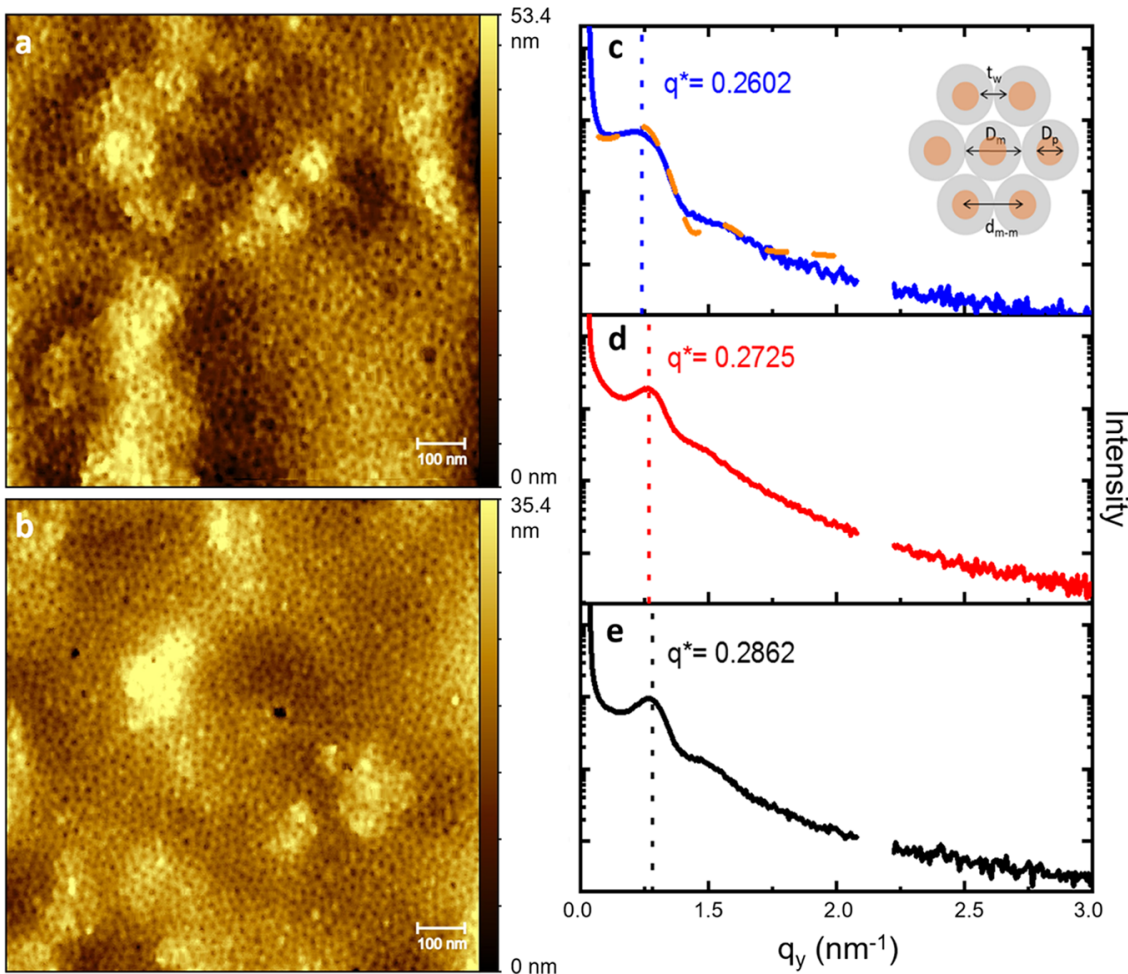

Figure 2. AFM images of (a) mesoporous $\mathrm{NC}_{5 \%}$ thin film following $8 \mathrm{~h}$ of $\mathrm{UV}_{254}$ exposure and (b) mesoporous $\mathrm{NC}_{5 \%}$ thin film produced only via thermal calcination. (c-e) GISAXS pattern linecuts along $q_{y}$ of $\mathrm{NC}_{5 \%}$ samples. (c) After thermal annealing with the BCP template still present. The dashed line represents a fit for spherical objects (diameter $26.3 \mathrm{~nm}$ ) arranged in a $2 \mathrm{D}$ hexagonal paracrystalline array. (d) After $8 \mathrm{~h}$ of $\mathrm{UV}_{254}$ exposure and (e) after thermal calcination at $450{ }^{\circ} \mathrm{C}$ (no UV exposure).

$1 \mathrm{e})$. Emerging porosities of $\approx 25$ and $\approx 30 \%$ were observed for $\mathrm{NC}_{5 \%}$ samples after 3 and $4 \mathrm{~h}$ of UV exposure (Figures $1 \mathrm{~b}$ and S3 of the Supporting Information), respectively, with a final porosity of $\approx 35 \%$ after $8 \mathrm{~h}$ of exposure. As expected, the porosity of $\mathrm{NC}_{0 \%}$ samples remained unchanged regardless of UV exposure time. This correlates with the trend observed from the refractive index analysis in Figure la.

To confirm that all organic material was removed from the $\mathrm{NC}_{5 \%}$ samples, Raman spectroscopy and XPS measurements were carried out (Figures S4 and S5, Supporting Information). For the Raman analysis, the peak at $920-1030 \mathrm{~cm}^{-1}$ found in all samples is consistent with the two-phonon silicon band of the silicon wafer substrate. ${ }^{43}$ A methylene stretching band was observed in the hybrid sample after thermal annealing but prior to template removal. ${ }^{44}$ However, neither the $\mathrm{UV}_{254}$ nor thermally calcined samples exhibited a peak in this region, indicating that in both approaches the organic material was successfully removed. The C 1s XPS spectrum (Figure S5, Supporting Information) of the thermally annealed sample before template removal (Figure S5a) presented an intense peak centered at $284 \mathrm{eV}$, attributed to the carbon-carbon single bonds in the polymer material. ${ }^{45}$ The intensity of this peak decreased dramatically following template removal by both $\mathrm{UV}_{254}$ (Figure S5b) and high-temperature calcination (Figure S5c), providing further evidence of the effectiveness of the $\mathrm{UV}_{254}$ technique in removing the template.

To probe the sample morphology and provide confirmation of the porous nature of the treated materials, AFM images were taken for $\mathrm{NC}_{5 \%}$ samples after $8 \mathrm{~h}$ of UV exposure (Figure 2a) and for samples that were treated with high-temperature calcination only (Figure 2b). These images confirm the presence of a porous inverse opal-type network when either template removal technique is applied. GISAXS measurements (Figures 2c-e, S6 and S7, Supporting Information) confirm that the $\mathrm{NC}_{5 \%}$ samples retained similar in-plane characteristics after $8 \mathrm{~h}$ of UV exposure and thermal calcination. The onedimensional GISAXS pattern for the hybrid $\mathrm{NC}_{5 \%}$ before template removal was fitted to a $2 \mathrm{D}$ hexagonal paracrystalline array of spherical objects $26.3 \mathrm{~nm}$ in diameter (Figure 2c). Simulated 2D GISAXS patterns (Figure S7, Supporting Information) support this assertion.

Increasing the amount of $\mathrm{TiO}_{2} \mathrm{NCs}$ in the formulation allows for tuning of the $\mathrm{UV}_{254}$ exposure time required for complete template removal. Figure 3 outlines the evolution of film porosity as a function of $\mathrm{UV}_{254}$ exposure and $\mathrm{TiO}_{2}$ loading through the respective adsorption isotherms. In contrast to the $\mathrm{NC}_{5 \%}$ results, porous networks were revealed in $\mathrm{NC}_{10 \%}$ and $\mathrm{NC}_{25 \%}$ after only $1 \mathrm{~h}$. In the case of $\mathrm{NC}_{10 \%}$, the increased photocatalytic activity was evidenced by an emerging porosity at intermediate stages, i.e., after $1 \mathrm{~h}(19 \%)$ and $2 \mathrm{~h}$ (33\%) with a leveling of porosity observed at $8 \mathrm{~h}$ of exposure. $\mathrm{NC}_{25 \%}$ continued this trend with all of the template being removed within the first $2 \mathrm{~h}$. A full statistical comparison of the obtained results as a function of $\mathrm{TiO}_{2}$ loading and UV exposure can be found in Figure S8 in the Supporting Information.

We note that the porosity observed for $\mathrm{UV}_{254}$-treated samples was typically $10-20 \%$ lower compared to that for those processed only by high-temperature calcination without $\mathrm{UV}_{254}$ (Figure S9, Supporting Information). The lower porosity values remained consistent irrespective of the amount of $\mathrm{TiO}_{2}$ loading. The results presented for a combinatorial treatment of $\mathrm{UV}_{254}$ exposure followed by high temperature calcination provide evidence that this observation was not related to residual organic material present in the UV 


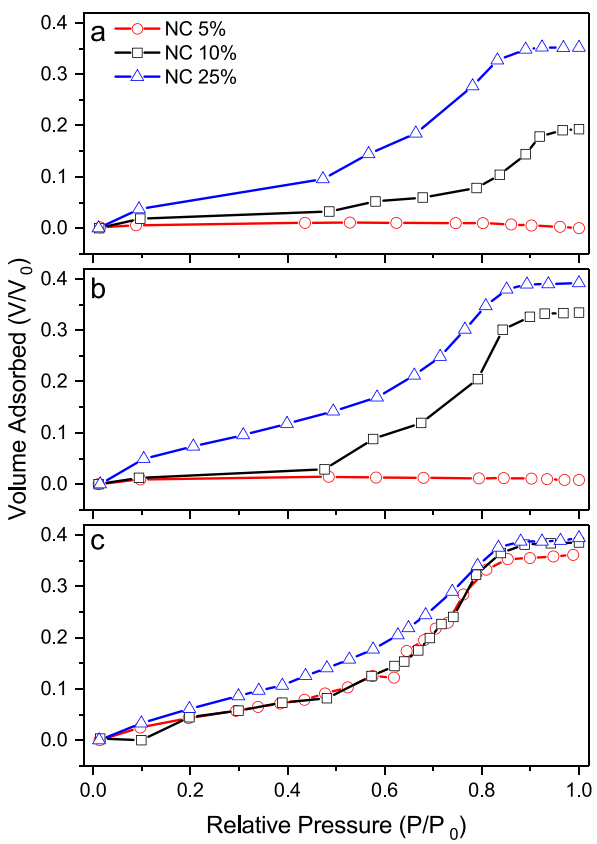

Figure 3. EP adsorption isotherms showing evolution of $\mathrm{NC}_{5 \%}$, $\mathrm{NC}_{10 \%}$, and $\mathrm{NC}_{25 \%}$ porosity as a function of $\mathrm{UV}$ exposure time: (a) after $1 \mathrm{~h},(\mathrm{~b})$ after $2 \mathrm{~h}$, and (c) after $8 \mathrm{~h}$.

degradation route. Analysis of the film compression provides an alternative explanation. The thickness of each sample was measured and compared using spectroscopic ellipsometry (Figure S10, Supporting Information). In each instance, samples exposed to UV for $8 \mathrm{~h}$ exhibited film shrinkage to a greater extent than observed in calcined counterparts. The additional film shrinkage impacted, in turn, the porosity of the film upon template removal. A combination of GISAXS and pore diameter data (Table S1, Supporting Information) obtained from EP measurements ${ }^{36}$ provides evidence that the wall thickness of the $\mathrm{NC}_{5 \%}$ was slightly higher in the UVtreated samples when compared to thermally calcined samples. As shown by the in-plane GISAXS patterns (Figure $2 c-e$ ), all samples maintained a similar structural composition regardless of the template removal treatment. While film shrinkage may impact the pore anisotropy, ${ }^{36}$ the actual porosity of the final film can be carefully tuned when using BCPs as structuredirecting agents, i.e., by varying the ratio of organic to inorganic precursors. ${ }^{1,15}$ Therefore, any variability of the porosity due to processing may be accommodated by minor modifications in the formulation.

\section{CONCLUSIONS}

We report the use of non-ozone-generating $\mathrm{UV}_{254}$ light for the low-temperature removal of block copolymer structuredirecting agents to prepare mesoporous aluminosilicate thin films. The incorporation of prefabricated $\mathrm{TiO}_{2}$ nanocrystals enables the photocatalytic cold combustion of the polymer material without the need for high-temperature treatment or ozone generation. Ellipsometric porosimetry and atomic force microscopy analyses showed that mesoporous networks could be generated using $\mathrm{TiO}_{2}$ loadings as low as $5 \%$ (with respect to the inorganic content) and UV exposure of $8 \mathrm{~h}$. Increasing the $\mathrm{TiO}_{2}$ loading allowed for shorter UV exposure times with similar results being observed. The $\mathrm{UV}_{254} / \mathrm{TiO}_{2}$ template removal method provides the advantage of reducing processing costs and allows for coating on temperature-sensitive substrates. Crucially, this technique offers environmental benefits as $\mathrm{UV}_{254}$ radiation produces zero ozone emissions while also enabling the use of next-generation LED technology whereby mercury is eliminated from the manufacturing process.

\section{ASSOCIATED CONTENT}

\section{S Supporting Information}

The Supporting Information is available free of charge on the ACS Publications website at DOI: 10.1021/acsami.9b01199.

X-ray diffraction of $\mathrm{TiO}_{2}$ nanocrystal powder; EP isotherms showing evolution of $\mathrm{NC}_{5 \%}$ as a function of UV exposure time; TEM images, Raman spectra, XPS spectra, and GISAXS patterns and analysis of $\mathrm{NC}_{5 \%}$ films; comparison of refractive index and porosity values in UV-treated and thermally calcined samples; film thickness change as a function of $\mathrm{TiO}_{2}$ content and UV exposure time; structural parameters for the film at different steps of the process obtained by GISAXS, ellipsometric porosimetry, and combination of both GISAXS and porosimetry (PDF)

\section{AUTHOR INFORMATION}

\section{Corresponding Author}

*E-mail: s.guldin@ucl.ac.uk.

\section{ORCID $\odot$}

Barry Reid: 0000-0002-4803-829X

Alaric Taylor: 0000-0001-6494-8309

Stefan Guldin: 0000-0002-4413-5527

Notes

The authors declare no competing financial interest.

\section{ACKNOWLEDGMENTS}

B.R. acknowledges funding by an EPSRC Industrial Case Award (EP/M506448/1) in support of BASF SE. A.T. recognizes support by the EPSRC Doctoral Training Partnership scheme (EP/M507970/1). We thank Dr. Han Wu and the EPSRC CNIE research facility service (EPSRC Award, EP/ $\mathrm{K} 038656 / 1)$ at the University College London for the collection of GISAXS data; Dr. Julia Weaving and Dr. Andy Leech from the University College London Electrical Innovation Lab (EIL) for collection of Raman spectroscopy and XRD data, respectively; Dr. Sanjayan Sathasivam from UCL Department of Chemistry for collection of XPS data; and Dr. Gemma-Louise Davies for collection of TEM data. B.R. wishes to thank Salma Conway for preparation of schematic images.

\section{REFERENCES}

(1) Reid, B.; Taylor, A.; Chen, Y.; Schmidt-Hansberg, B.; Guldin, S. Robust Operation of Mesoporous Antireflective Coatings under Variable Ambient Conditions. ACS Appl. Mater. Interfaces 2018, 10, 10315-10321.

(2) Haque, M. A.; Sheikh, A. D.; Guan, X.; Wu, T. Metal Oxides as Efficient Charge Transporters in Perovskite Solar Cells. Adv. Energy Mater. 2017, 7, No. 1602803.

(3) Li, W.; Liu, J.; Zhao, D. Mesoporous Materials for Energy Conversion and Storage Devices. Nat. Rev. Mater. 2016, 1, No. 16023.

(4) Choi, H.; Stathatos, E.; Dionysiou, D. D. Sol-gel Preparation of Mesoporous Photocatalytic $\mathrm{TiO}_{2}$ Films and $\mathrm{TiO}_{2} / \mathrm{Al}_{2} \mathrm{O}_{3}$ Composite 
Membranes for Environmental Applications. Appl. Catal., B 2006, 63, $60-67$.

(5) Rodríguez, R. C.; Bruno, M. M.; Angelomé, P. C. Au Nanoparticles Embedded in Mesoporous $\mathrm{ZrO}_{2}$ films: Multifunctional Materials for Electrochemical Detection. Appl. Catal., B 2018, 254, $603-612$.

(6) Nicole, L.; Laberty, C.; Sanchez, C.; Boissière, C.; Grosso, D. Design, Synthesis, and Properties of Inorganic and Hybrid Thin Films Having Periodically Organized Nanoporosity. Chem. Mater. 2008, 20, 682-737.

(7) Thomas, I. M. Method for the Preparation of Porous Silica Antireflection Coatings Varying in Refractive Index from 1.22 to 1.44. Appl. Opt. 1992, 31, No. 6145.

(8) López-López, C.; Colodrero, S.; Raga, S. R.; Lindström, H.; Fabregat-Santiago, F.; Bisquert, J.; Míguez, H. Enhanced Diffusion through Porous Nanoparticle Optical Multilayers. J. Mater. Chem. 2012, 22, 1751-1757.

(9) Du, Y.; Luna, L. E.; Tan, W. S.; Rubner, M. F.; Cohen, R. E. Hollow Silica Nanoparticles in UV-Visible Antireflection Coatings for Poly(methyl methacrylate) Substrates. ACS Nano 2010, 4, 43084316.

(10) Moghal, J.; Kobler, J.; Sauer, J.; Best, J.; Gardener, M.; Watt, A. A.; Wakefield, G. High-Performance, Single-Layer Antireflective Optical Coatings Comprising Mesoporous Silica Nanoparticles. ACS Appl. Mater. Interfaces 2012, 4, 854-859.

(11) Yang, H.; Coombs, N.; Sokolov, I.; Ozin, G. A. Free-Standing and Oriented Mesoporous Silica Films Grown at the Air-Water Interface. Nature 1996, 381, 589-592.

(12) Innocenzi, P.; Malfatti, L. Mesoporous Thin Films: Properties and Applications. Chem. Soc. Rev. 2013, 42, 4198.

(13) Hatton, B.; Mishchenko, L.; Davis, S.; Sandhage, K. H.; Aizenberg, J. Assembly of Large-Area, Highly-Ordered, Crack-free Inverse Opal Films. Proc. Natl. Acad. Sci. U.S.A. 2010, 107, 1035410359.

(14) Guldin, S.; Kolle, M.; Stefik, M.; Langford, R.; Eder, D.; Wiesner, U.; Steiner, U. Tunable Mesoporous Bragg Reflectors Based on Block-Copolymer Self-Assembly. Adv. Mater. 2011, 23, 36643668.

(15) Guldin, S.; Kohn, P.; Stefik, M.; Song, J.; Divitini, G.; Ecarla, F.; Ducati, C.; Wiesner, U.; Steiner, U. Self-Cleaning Antireflective Optical Coatings. Nano Lett. 2013, 13, 5329-5335.

(16) Lokupitiya, H. N.; Jones, A.; Reid, B.; Guldin, S.; Stefik, M. Ordered Mesoporous to Macroporous Oxides with Tunable Isomorphic Architectures: Solution Criteria for Persistent Micelle Templates. Chem. Mater. 2016, 28, 1653-1667.

(17) Gomez-Vega, J. M.; Teshima, K.; Hozumi, A.; Sugimura, H.; Takai, O. Mesoporous Silica Thin Films Produced by Calcination in Oxygen Plasma. Surf. Coat. Technol. 2003, 169-170, 504-507.

(18) Galusha, J. W.; Richey, L. R.; Jorgensen, M. R.; Gardner, J. S.; Bartl, M. H. Study of Natural Photonic Crystals in Beetle Scales and their Conversion into Inorganic Structures via a Sol-Gel BioTemplating Route. J. Mater. Chem. 2010, 20, 1277-1284.

(19) Hatton, B. D.; Landskron, K.; Whitnall, W.; Perovic, D. D.; Ozin, G. A. Spin-Coated Periodic Mesoporous Organosilica Thin Films - Towards a New Generation of Low-Dielectric-Constant Materials. Adv. Funct. Mater. 2005, 15, 823-829.

(20) Wirnsberger, G.; Scott, B. J.; Stucky, G. D. pH Sensing with Mesoporous Thin Films. Chem. Commun. 2001, 119-120.

(21) Clark, T.; Ruiz, J. D.; Fan, H.; Brinker, C. J.; Swanson, B. I.; Parikh, A. N. A New Application of UV-Ozone Treatment in the Preparation of Substrate-Supported, Mesoporous Thin Films. Chem. Mater. 2000, 12, 3879-3884.

(22) Okido, A.; Hozumi, Y.; Yokogawa, T.; Kameyama, K.; Hiraku, H.; Sugimura, O.; Takai, M. Photocalcination of Mesoporous Silica Films Using Vacuum Ultraviolet Light. Adv. Mater. 2000, 12, 985987.

(23) Hozumi, A.; Sugimura, H.; Hiraku, K.; Kameyama, T.; Takai, O. Low-Temperature Elimination of Organic Components from
Mesostructured Organic-Inorganic Composite Films Using Vacuum Ultraviolet Light. Chem. Mater. 2000, 12, 3842-3847.

(24) Bell, M. L.; Peng, R. D.; Dominici, F. The Exposure-Response Curve for Ozone and Risk of Mortality and the Adequacy of Current Ozone Regulations. Environ. Health Perspect. 2006, 114, 532-536.

(25) Muramoto, Y.; Kimura, M.; Nouda, S. Development and Future of Ultraviolet Light-emitting Diodes: UV-LED will Replace the UV Lamp. Semicond. Sci. Technol. 2014, 29, No. 084004.

(26) De Paz-Simon, H.; Chemtob, A.; Croutxé-Barghorn, C.; Rigolet, S.; Michelin, L.; Vidal, L.; Lebeau, B. Periodic Mesostructured Silica Films Made Simple Using UV Light. J. Phys. Chem. C 2014, 118, 4959-4966.

(27) Xiao, L.; Li, J.; Jin, H.; Xu, R. Removal of Organic Templates from Mesoporous SBA-15 at Room Temperature using UV/dilute $\mathrm{H}_{2} \mathrm{O}_{2}$. Microporous Mesoporous Mater. 2006, 96, 413-418.

(28) Niederberger, M.; Bartl, M. H.; Stucky, G. D. Benzyl Alcohol and Titanium Tetrachloride: A Versatile Reaction System for the Nonaqueous and Low-temperature Preparation of Crystalline and Luminescent Titania Nanoparticles. Chem. Mater. 2002, 14, 43644370.

(29) Parkin, I. P.; Palgrave, R. G. Self-Cleaning Coatings. J. Mater. Chem. 2005, 15, 1689-1695.

(30) Kohn, P.; Pathak, S.; Stefik, M.; Ducati, C.; Wiesner, U.; Steiner, U.; Guldin, S. Low temperature crystallisation of mesoporous $\mathrm{TiO}_{2}$. Nanoscale 2013, 5, 10518-10524.

(31) Brezesinski, T.; Wang, J.; Polleux, J.; Dunn, B.; Tolbert, S. H. Templated Nanocrystal-based Porous $\mathrm{TiO}_{2}$ Films for Next-generation Electrochemical Capacitors. J. Am. Chem. Soc. 2009, 131, 1802-1809.

(32) Szeifert, J. M.; Fattakhova-Rohlfing, D.; Georgiadou, D.; Kalousek, V.; Rathouský, J.; Kuang, D.; Wenger, S.; Zakeeruddin, S. M.; Grätzel, M.; Bein, T. Brick and Mortar Strategy for the Formation of Highly Crystalline Mesoporous Titania Films from Nanocrystalline Building Blocks. Chem. Mater. 2009, 21, 1260-1265.

(33) Hartmann, P.; Lee, D.-K.; Smarsly, B. M.; Janek, J. Mesoporous $\mathrm{TiO}_{2}$ : Comparison of Classical Sol-Gel and Nanoparticle Based Photoelectrodes for the Water Splitting Reaction. ACS Nano 2010, 4, $3147-3154$

(34) von Graberg, T.; Hartmann, P.; Rein, A.; Gross, S.; Seelandt, B.; Röger, C.; Zieba, R.; Traut, A.; Wark, M.; Janek, J.; Smarsly, B. M. Mesoporous tin-doped indium oxide thin films: effect of mesostructure on electrical conductivity. Sci. Technol. Adv. Mater. 2011, 12, No. 025005 .

(35) Baklanov, M. R.; Mogilnikov, K. P.; Polovinkin, V. G.; Dultsev, F. N. Determination of Pore Size Distribution in Thin Films by Ellipsometric Porosimetry. J. Vac. Sci. Technol., B: Microelectron. Nanometer Struct.-Process., Meas., Phenom. 2000, 18, 1385.

(36) Boissiere, C.; Grosso, D.; Lepoutre, S.; Nicole, L.; Bruneau, A. B.; Sanchez, C. Porosity and Mechanical Properties of Mesoporous Thin Films Assessed by Environmental Ellipsometric Porosimetry. Langmuir 2005, 21, 12362-12371.

(37) Babonneau, D. FitGISAXS: Software Package for Modelling and Analysis of GISAXS Data using IGOR Pro. J. Appl. Crystallogr. 2010, 43, 929-936.

(38) Jain, A.; Wiesner, U. Silica-Type Mesostructures from Block Copolymer Phases: Formation Mechanism and Generalization to the Dense Nanoparticle Regime. Macromolecules 2004, 37, 5665-5670.

(39) Fujiwara, H. Spectroscopic Ellipsometry: Principles and Applications; John Wiley \& Sons, Ltd: Chichester, U.K., 2007.

(40) Sing, K. S. W. Reporting Physisorption Data for Gas/Solid Systems with Special Reference to the Determination of Surface Area and Porosity. Pure Appl. Chem. 1985, 57, 603-619.

(41) Grosman, A.; Ortega, C. Capillary Condensation in Porous Materials. Hysteresis and Interaction Mechanism without Pore Blocking/Percolation Process. Langmuir 2008, 24, 3977-3986.

(42) Etienne, M.; Quach, A.; Grosso, D.; Nicole, L.; Sanchez, C.; Walcarius, A. Molecular Transport into Mesostructured Silica Thin Films: Electrochemical Monitoring and Comparison Between p6m, $\mathrm{P}_{3} / \mathrm{mmc}$, and Pm3n Structures. Chem. Mater. 2007, 19, 844-856. 
(43) Borowicz, P.; Latek, M.; Rzodkiewicz, W.; Łaszcz, A.; Czerwinski, A.; Ratajczak, J. Deep-ultraviolet Raman Investigation of Silicon Oxide: Thin Film on Silicon Substrate versus Bulk Material. Adv. Nat. Sci.: Nanosci. Nanotechnol. 2012, 3, No. 045003.

(44) Colthup, N. B. Introduction to Infrared and Raman Spectroscopy, 3rd ed.; Colthup, N. B., Daly, L. H., Wiberley, S. E., Eds.; Academic Press: Boston, Mass.; London, 1990.

(45) Ermolieff, A.; Chabli, A.; Pierre, F.; Rolland, G.; Rouchon, D.; Vannuffel, C.; Vergnaud, C.; Baylet, J.; Séméria, M. N. XPS, Raman Spectroscopy, X-ray Diffraction, specular X-ray Reflectivity, Transmission Electron Microscopy and Elastic Recoil Detection Analysis of Emissive Carbon Film Characterization. Surf. Interface Anal. 2001, 31, 185-190. 